\title{
OPTIMIZED AQUIFER MANAGEMENT, USING LINEAR PROGRAMMING. AN APPLICATION TO THE AGIA VARVARA AQUIFER, DRAMA, GREECE
}

\section{TZIMOPOULOS* \\ P. GINIDI}

Selected from papers presented in $8^{\text {th }}$ International Conference on Environmental Science and Technology (8CEST2003) 8-10 September 2003, Lemnos island, Greece
Aristotle University of Thessaloniki

Department of Rural and Surveying Engineering

Division of Transportation and Hydraulics Engineering AUTH- 54124, Thessaloniki, Greece

*to whom all correspondence should be addressed e-mail: tzimop@vergina.eng.auth.gr

\begin{abstract}
The present research analyzes the behavior of Agia Varvara aquifer in Drama, Greece. A comprehensive and complete simulation-management combination model is applied, capable of calculating the water mass balance of the aquifer and defining the optimal management solution. In order to simulate the aquifer, a finite difference model is used. By applying this model and the Response Matrix Method, the management of the aquifer is achieved. Once the simulation of the aquifer is finished, the Linear Programming analysis is performed to obtain the optimal values of piezometric heads and flow rates, imposed to the system on monthly basis, in order to meet the demand of water at the lowest cost. The resulting piezometric heads are compared with the initial ones, enabling scenarios about the maximum and minimum drawdown, and providing the critical months of irrigation. The Linear Programming is used to facilitate the operation of systems, maximizing the total amount of pumped water, under a given set of constraints.
\end{abstract}

KEYWORDS: Water resources management, Linear Programming, Response Matrix Method.

\section{INTRODUCTION}

The increase of water demand has created a lot of problems in the last years and the imperative need to develop water resources management plans in the world. As groundwater represents one of the most important resources, many of the plans are related to the exploitation of aquifers. Numerical methods have been developed, until now, to simulate the ground water and Linear Programming methods have been applied to minimize the total cost of the pumped water.

Several groundwater flow models have been developed by researchers and technical software houses during the last decades. First of all, Schwarz (1971) presented an example of optimal groundwater management, using Linear Programming. He had chosen a two-dimensional rectangular grid of 25 cells, in order to represent the aquifer system. Bear (1979) also described the combination of both management and optimization problems. Mc Donald \& Harbaugh (1988) dealt with the development of 3D groundwater model and solved it through a multilevel iterative process, based on finite differences method. Greenwald (1994) had cooperated with Mc Donald \& Harbaugh and provided optimization techniques in conjunction with the respective software support, in order to solve the groundwater and irrigation problems. 
A large number of publications also exist on the application of Linear Programming to the management of water resources. N.K. Garg and Abbas Ali (1997) dealt with the application of a Linear and Integer Programming model to Dadu canal command of Lower Indus Basin. A.A. Psilovikos (1998) compared two optimization methods, based on Linear and Mixed Integer Programming, combining primarily the simulation model MODFLOW with the management one MODMAN and optimization LINDO.

There are many other well mentioned publications, focus on optimized operations in water management. For example, Arnold H. Lobbrecht (1994) described an optimized control strategy, under changing objectives and dynamic boundary condition, in a rural water management system in Netherlands. A.S. Reeve et al. (1999) analyzed how the groundwater flow simulations are used to evaluate the importance of three parameters on vertical flow in peat lands: regional slope, permeability of the mineral soil and peat land topography, etc.

In this study, a simulation-management-optimization model has been developed to obtain the optimum piezometric heads and flow rates, as well as to maximize the total amount of pumped water. The aquifer system of Agia Varvara has been used as a case study for this project.

\section{THE STUDY AREA AND SIMULATED FEATURES}

Agia Varvara's region in Northern Greece was used as an application example for the simulation- management combination model (Ginidi, 2002). The watershed is located near the city of Drama and includes a considerable part of Falakro Mountain. The watershed's area is $218,91 \mathrm{~km}^{2}$, belonging to the geological zone of Rodopi, where 18 wells $\left(W_{1}-W_{18}\right)$ and 2 springs (figure 1 ) are operating. In the same figure, the wells named $\mathrm{W}_{19}-\mathrm{W}_{24}$ also appear, but they are not included in the calculations, because their flow rates are too small. The presence of low permeability materials in the top and the bottom of the aquifer indicates that the aquifer behaves as a confined system.

The aquifer is geometrically divided into a rectangular grid of $23 \times 33$ cells, whose dimensions are $500 \times 500 \mathrm{~m}$, and the main thickness of the aquifer is about $70 \mathrm{~m}$. There are 159 non-contributing cells located southeast and southwest in the grid and are represented as inactive points of the modeled area.

The location of the wells in the studied aquifer is indicated in the Figure 1.

Hydraulic and geometrical data have been obtained from the meteorological station of Drama. The mean annual precipitation from 1931 to 1993, corresponding to the hydrological basin of Drama, is $632,1 \mathrm{~mm}$.

The main parameters required for the simulation procedure are introduced in the program of MODFLOW by PMCAD preprocessor cell-by-cell and are the following:

- top and bottom layer of the aquifer [L],

- boundary array ( 0 for inactive cells, 1 for the active ones and -1 for constant head cells),

- porosity,

- specific storativity $\left[\mathrm{L}^{-1}\right]$,

- hydraulic conductivity $\left[\mathrm{L} \mathrm{T}^{-1}\right]$,

- initial piezometric heads [L].

Wells existing inside the borders of the hydrological basin, can operate either periodically (irrigation wells), that is from May to September, or continually (industry and water supply wells). The total monthly amount of pumping rates, springs, recharges from the top cells of the grid and precipitation can be illustrated in figure 2 . 


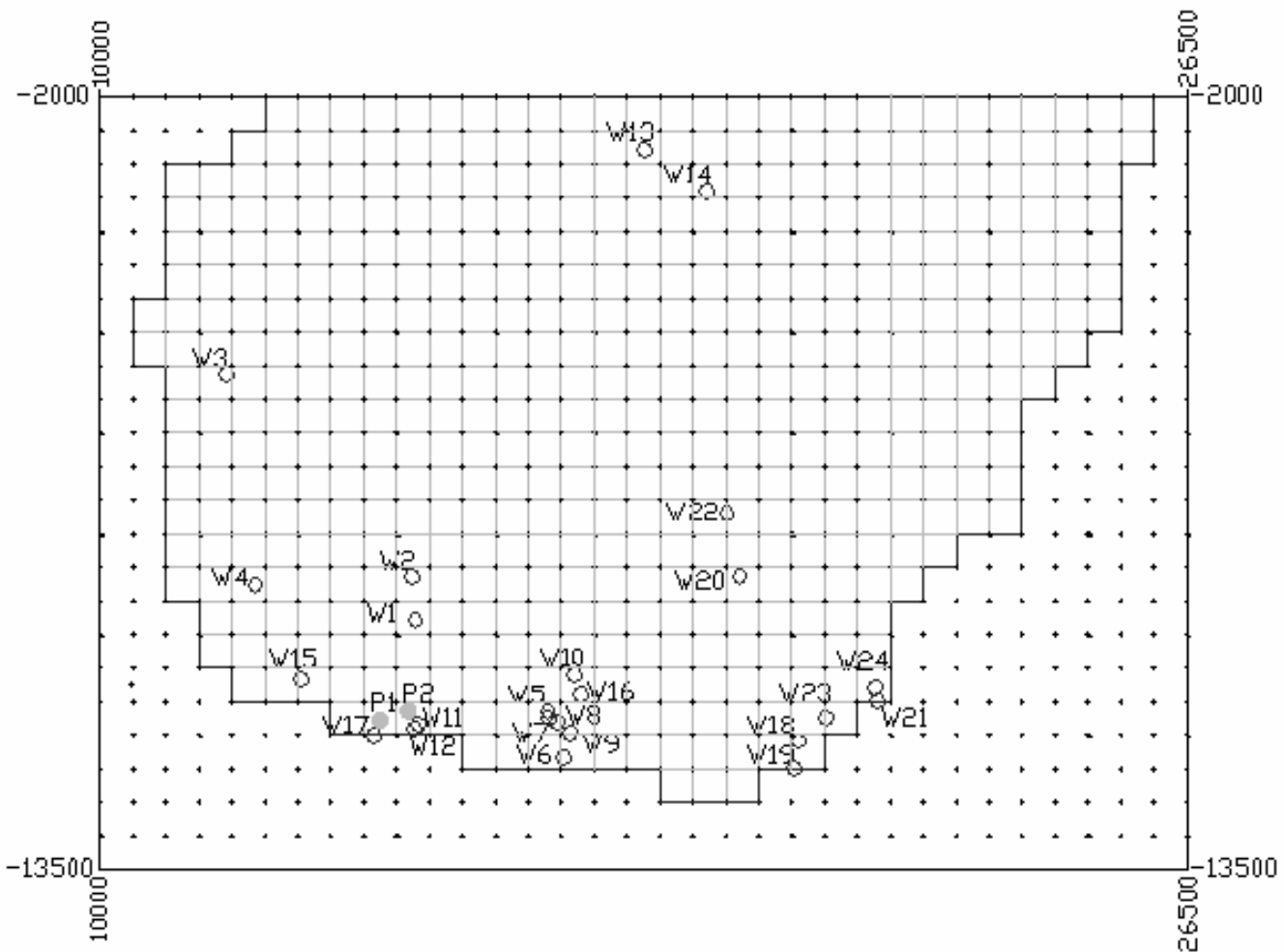

Figure 1. Wells location and borders of the studied area

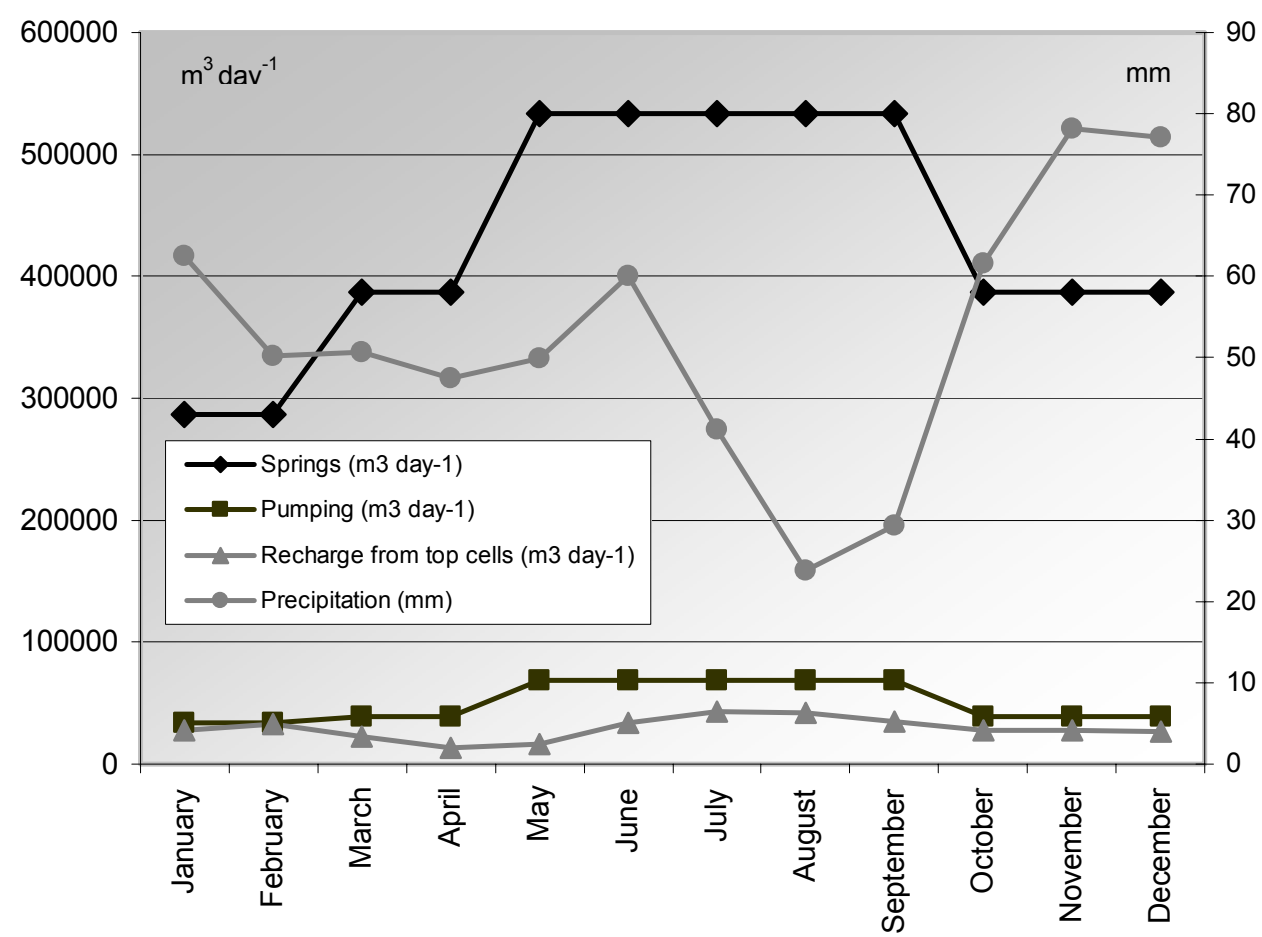

Figure 2. Pumping rates recharges from top cells, precipitation and springs

Initial head conditions of the aquifer can be shown in the following three-dimensional figure: 


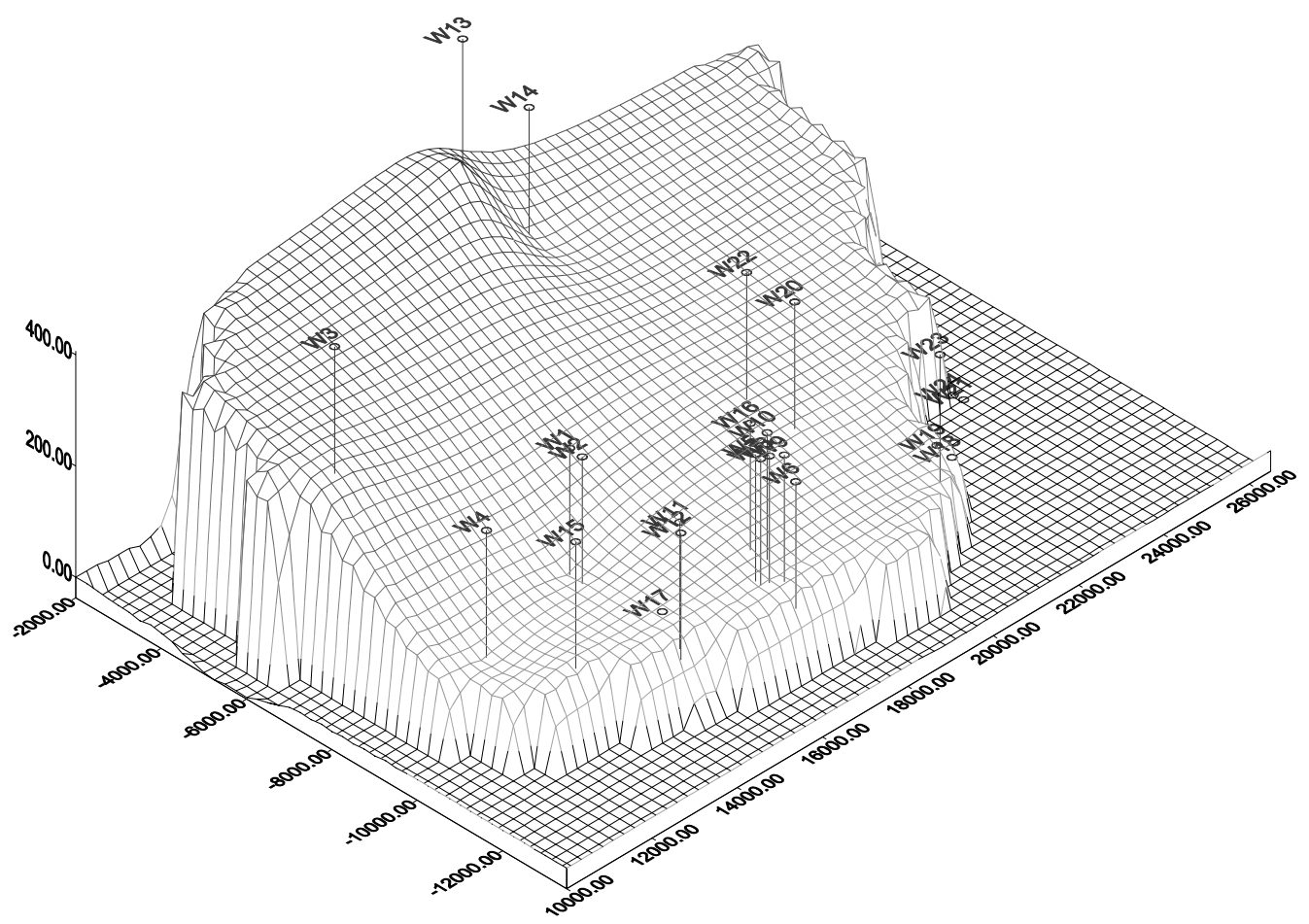

Figure 3. Initial piezometric head of the aquifer

Groundwater flow simulations were performed using MODFLOW program (Mc Donald and Harbaugh, 1988), which numerically evaluates the following partial differential equations (Bear, 1979) for ground-water flow, using a block-centered finite-difference method:

$\frac{\partial}{\partial x} \cdot\left(K_{x x} \frac{\partial h}{\partial x}\right)+\frac{\partial}{\partial y} \cdot\left(K_{y y} \frac{\partial h}{\partial y}\right)+\frac{\partial}{\partial z} \cdot\left(K_{z z} \frac{\partial h}{\partial z}\right)-W=S_{s} \cdot \frac{\partial h}{\partial t}$

where:

$\mathrm{K}_{\mathrm{xx}}, \mathrm{K}_{\mathrm{yy}}, \mathrm{K}_{\mathrm{zz}}$ are values of hydraulic conductivity along $\mathrm{x}, \mathrm{y}, \mathrm{z}$ coordinate axes which are assumed to be parallel to the major axes of hydraulic conductivity $\left[\mathrm{L} \mathrm{T}^{-1}\right]$,

$\mathrm{h}$ is the piezometric head $[\mathrm{L}]$,

$W$ is the Source/Sink term $\left[\mathrm{T}^{-1}\right]$,

$\mathrm{S}_{\mathrm{s}}$ is the specific storativity $\left[\mathrm{L}^{-1}\right]$,

$\mathrm{t}$ is the time [T].

The results of MODFLOW simulation indicated that the water level of the aquifer takes its minimum value on September, considered to be the most critical month, meaning the end of pumping period (Figure 4). The drawdown in that case is quite obvious, compared with the initial head position (Figure 3).

The simulation resulting piezometer of the aquifer in cross section $y=-9750$ is illustrated in Figure 5. 


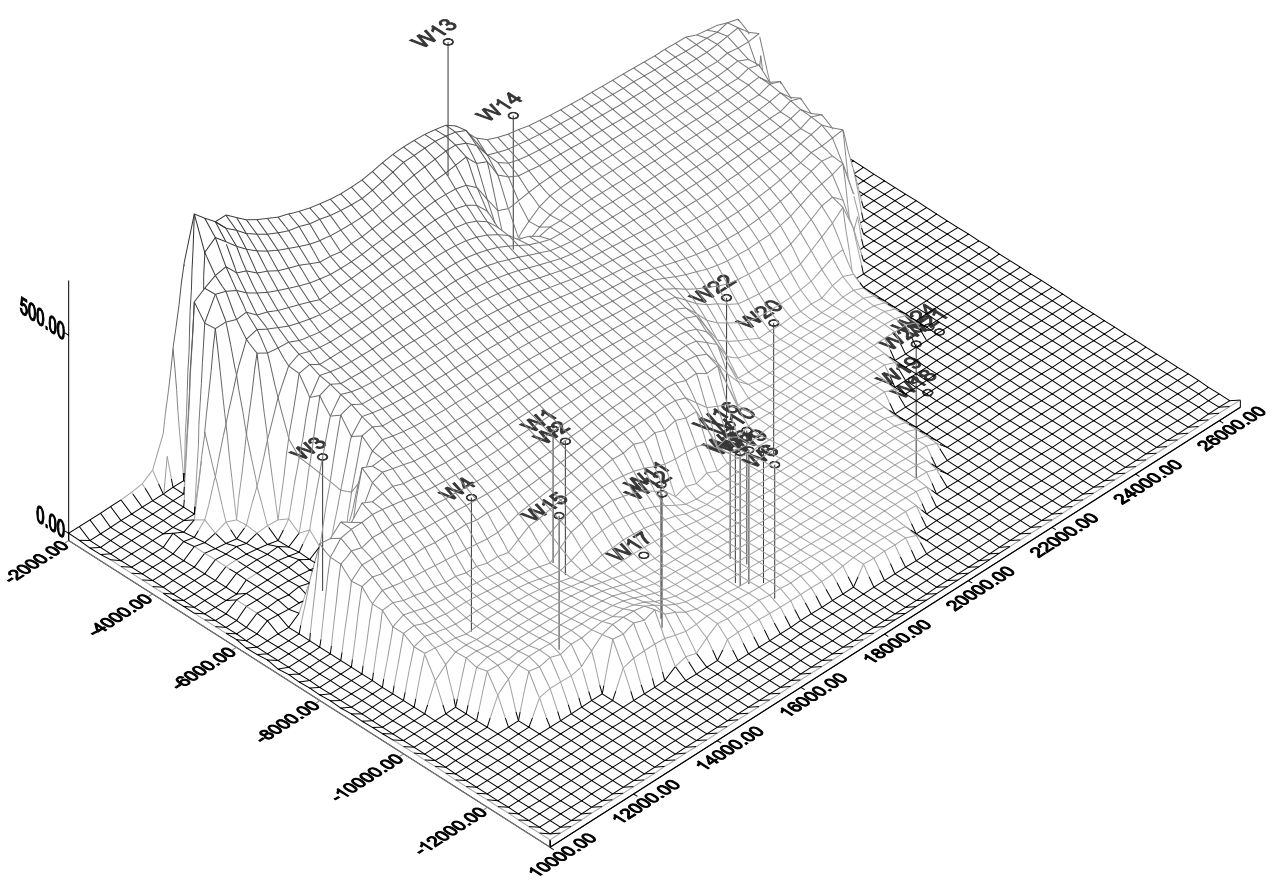

Figure 4. Piezometric head of the aquifer in the end of pumping period

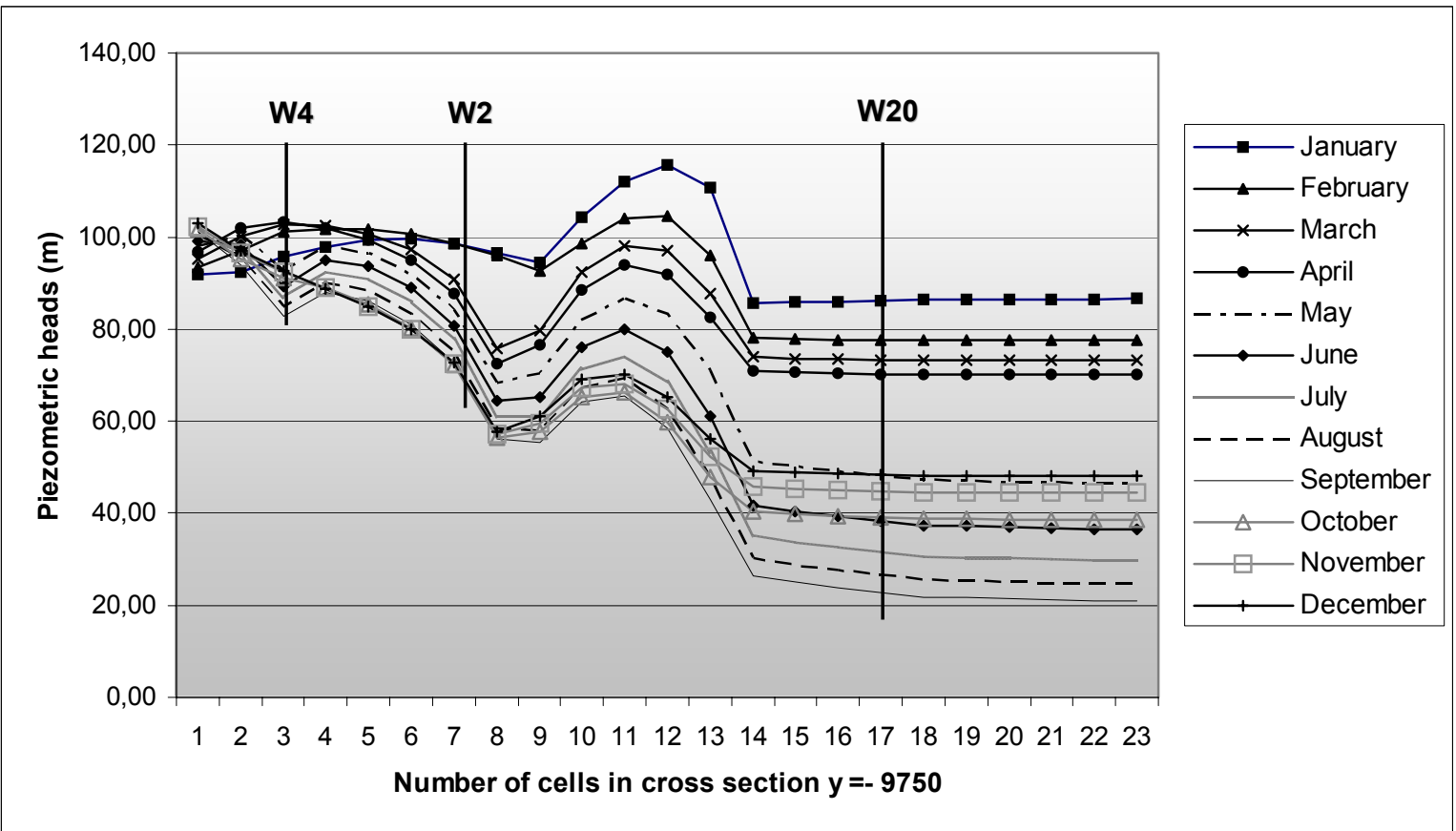

Figure 5. Piezometric heads in cross section $y=-9750$

\section{USE OF THE RESPONSE MATRIX METHOD AND STATEMENT OF THE OPTIMIZATION PROBLEM}

\subsection{Management}

Before stating the management problem, a link between the management problem and the simulation model is needed. The MODMAN program (Greenwald, 1994) is a management module, based on a new code, operating as a link for MODFLOW (the finite-difference model for groundwater flow simulation in three dimensions) and LINDO 
(the model for the optimization procedure). In conjunction with the Linear Programming approach, MODMAN can provide information about the exact pumping location, as well as the flow rate of water extraction or injection.

MODMAN enables a variety of three dimensional groundwater management problems to be solved via the Response Matrix Method. Consequently, with this technique the physical problem can be approximated as a linear mathematical one. To define the response coefficients for a managed well, a unit rate is applied at that well in stress period 1, while all the other managed wells are turned off. Drawdown responses in all periods are calculated in terms of a unit rate applied in stress period 1 . The reason is that drawdown in each period is not only induced by pumping in that specific period, but also by pumping in previous times. With the Response Matrix Method the total drawdown from the simultaneous function of all the other wells can be calculated. The case of unsteady flow is examined in this paper and is expressed as follows:

$\mathrm{h}_{\mathrm{i}}^{\top}=\mathrm{U}_{\mathrm{i}}^{\top}-\sum_{\mathrm{k}=1}^{\mathrm{T}} \sum_{\mathrm{j}=1}^{\mathrm{N}} \alpha_{\mathrm{ij}}^{\top-(\mathrm{k}-1)} \cdot \mathrm{Q}_{\mathrm{j}}^{\mathrm{k}}$

where:

$h_{i}^{\top}$ is the managed piezometric head at control point $i$ at the end of the last managing period $\mathrm{T}$,

$U_{i}^{\top}$ is the unmanaged piezometric head at control point $i$ at the end of the last managing period $\mathrm{T}$,

$\alpha_{i j}^{T-(k-1)}$ is the average drawdown in each i observation well at the end of the T pumping period, due to a unit rate of pumping at the $\mathrm{j}$ managed well applied throughout the $\mathrm{k}$ pumping period (Colarrulo et al., 1984) and

$Q_{j}^{K}$ is the pumping rate at well $j$ during the k pumping period.

During the operation of the MODMAN program the following files are created:

$\Rightarrow$ moderr comprising of MODMAN program's errors.

$\Rightarrow$ modout including the management results.

$\Rightarrow$ modflow output indicating the steps of the iterative process.

$\Rightarrow$ modmps where the cost coefficients of the objective function are registered.

Modmps file must be modified with the suitable cost coefficient values, because the existing ones are corresponding to a unit rate equal to 1 . Results concerning optimal values of piezometric heads and flow rates are registered to modopt file.

MODMAN procedure is illustrated in the following diagram:

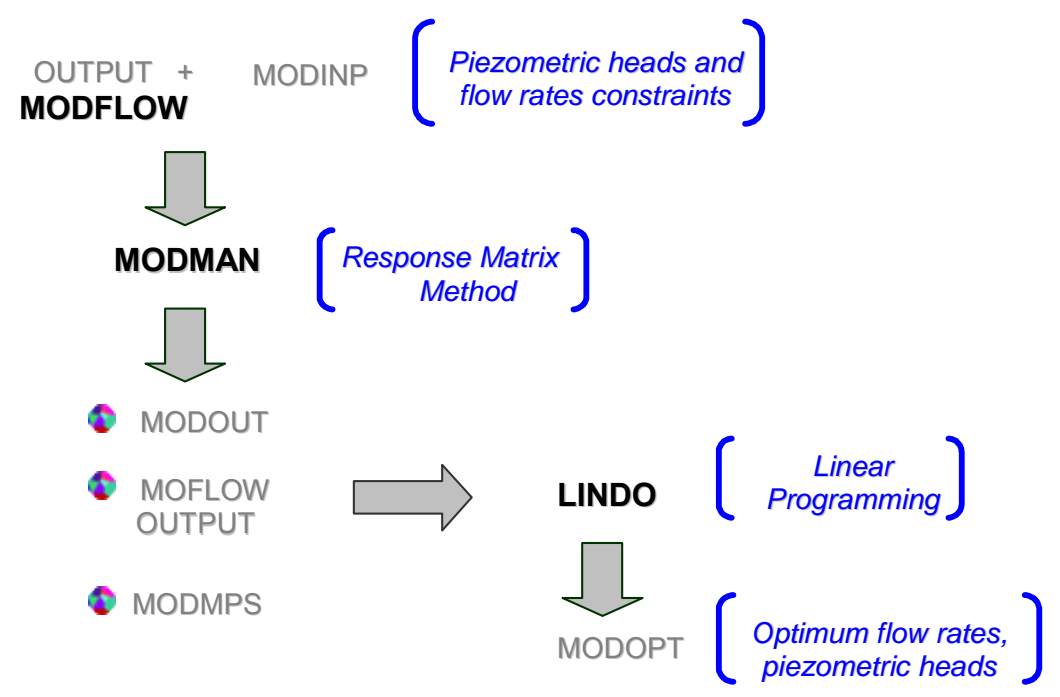

Figure 6. Schematic diagram of MODMAN procedure 


\subsection{Optimization}

The task of the optimization process is to determine the maximum flow rate that can be pumped from a certain number of wells, subject to a given set of constraints limiting the drawdown values (Psilovikos, 1999).

Assuming that the objective function - the total amount of water to be pumped - and the constraints are a linear function of pumping rates, the groundwater management problem can be formulated as a standard Linear Programming optimization problem, solved by the Simplex Algorithm and using the LINDO program (Schrage 1991). Therefore, the objective function becomes:

Maximize $f=\sum_{i=1}^{N} \alpha_{i} \cdot Q_{i}$,

where $\alpha_{i}$ are the cost coefficients.

All combined constraints describe the feasible region for the solution of the optimization problem. These constraints, representing in this case the piezometric heads in specific control points in the aquifer, are given as follows: (Psilovikos A. and Tzimopoulos C., 1998).

$\Delta h_{i}^{k}=U_{i}^{k}-H_{i}^{k}=\sum_{k=1}^{T} \sum_{j=1}^{N} \alpha_{i j}^{\top-(k-1)} \cdot Q_{j}^{k} \leq b_{i}^{\top}=U_{i}^{\top}-H_{i, m i n}^{\top}$

As far as quantity is concerned, the demand for water on a monthly basis must be equal to the total amount of water to be pumped from the aquifer. This restriction can be achieved by imposing a groundwater balance constraint and is expressed as:

$\sum_{k=1}^{T} \sum_{j=1}^{N} Q_{j}^{k}=c t$

where:

$\mathrm{i}$ is the control point in piezometric level, $\mathrm{j}$ is the pumping well,

$\mathrm{k}$ is the managing period,

$\mathrm{T}$ is the time period,

$\mathrm{H}_{\mathrm{i}}^{\mathrm{k}}$ is the managed head at control point $\mathrm{i}$ during the $\mathrm{k}$ managing period,

$b_{i}^{\top}$ is the maximum managed drawdown at control point $i$ at the end of the last irrigation period $\mathrm{T}$ and

$\mathrm{H}_{\mathrm{i}, \mathrm{min}}^{\mathrm{T}}$ is the minimum allowable head at control point $\mathrm{i}$ at the end of the last irrigation period $\mathrm{T}$.

The program output gives, for every iteration step, the value of the objective function and the optimal values of the original variables of the groundwater problem.

In the application of the optimization model to the management of Agia Varvara aquifer, flow rates represent pumping and so they have negative values. Therefore, the target is the maximization of the objective function, which, in this case of 18 wells, can be mathematically expressed as follows:

$$
\begin{aligned}
& \operatorname{maxf}(x)=C_{i}^{k} \cdot Q_{i}^{k}=C_{W 1}^{1} \cdot Q_{W 1}^{1}+C_{W 1}^{2} \cdot Q_{W 1}^{2}+\ldots \ldots .+C_{W 1}^{12} \cdot Q_{W 1}^{12}+C_{W 2}^{1} \cdot Q_{W 2}^{1} \\
& +C_{W 2}^{2} \cdot Q_{W 2}^{2}+\ldots .+C_{W 2}^{12} \cdot Q_{W 2}^{12}+C_{W 3}^{1} \cdot Q_{W 3}^{1}+\ldots . . C_{W 3}^{12} \cdot Q_{W 3}^{12}+C_{W 4}^{1} \cdot Q_{W 4}^{1}+\ldots . \\
& +C_{W 4}^{12} \cdot Q_{W 4}^{12}+\ldots \ldots . C_{W 18}^{1} \cdot Q_{W 18}^{1}+\ldots . .+C_{W 18}^{12} \cdot Q_{W 18}^{12}
\end{aligned}
$$

where:

i Managed well $\left(i=W_{1}, W_{2}, W_{3}, W_{4}, \ldots \ldots W_{18}\right)$,

$\mathrm{k}$ Managing period $\mathrm{k}=1,2 \ldots .12$

Piezometric head constraints are based on equation 4 and are formulated taking into account the end of the irrigation period, which is September, and the last month of the 
study. Equation 5 gives the groundwater balance constraints of Agia Varvara aquifer for each time step as follows:

$$
\begin{aligned}
& \sum Q_{i}^{1}=Q_{W 1}^{1}+Q_{W 2}^{1}+\ldots \ldots \ldots . .+Q_{W 18}^{1}=-21464 m^{3} \text { day }^{-1} \\
& \sum Q_{i}^{2}=Q_{W 1}^{2}+Q_{W 2}^{2}+\ldots \ldots \ldots . .+Q_{W 18}^{2}=-20464 m^{3} \text { day }^{-1} \\
& \sum Q_{i}^{3}=Q_{W 1}^{3}+Q_{W 2}^{3}+\ldots \ldots \ldots . .+Q_{W 18}^{3}=-27464 \mathrm{~m}^{3} \text { day }^{-1} \\
& \sum Q_{i}^{4}=Q_{W 1}^{4}+Q_{W 2}^{4}+\ldots \ldots \ldots . .+Q_{W 18}^{4}=-26464 m^{3} \text { day }^{-1} \\
& \sum Q_{i}^{5}=Q_{W 1}^{5}+Q_{W 2}^{5}+\ldots \ldots \ldots .+Q_{W 18}^{5}=-48136 \mathrm{~m}^{3} \text { day }^{-1} \\
& \sum Q_{i}^{6}=Q_{W 1}^{6}+Q_{W 2}^{6}+\ldots \ldots \ldots . .+Q_{W 18}^{6}=-48136 \mathrm{~m}^{3} \text { day }^{-1} \\
& \sum Q_{i}^{7}=Q_{W 1}^{7}+Q_{W 2}^{7}+\ldots \ldots \ldots . .+Q_{W 18}^{7}=-47136 \mathrm{~m}^{3} \text { day }^{-1} \\
& \sum Q_{i}^{8}=Q_{W 1}^{8}+Q_{W 2}^{8}+\ldots \ldots \ldots . .+Q_{W 18}^{8}=-48136 \mathrm{~m}^{3} \text { day }^{-1} \\
& \sum Q_{i}^{9}=Q_{W 1}^{9}+Q_{W 2}^{9}+\ldots \ldots \ldots . .+Q_{W 18}^{9}=-46136 \mathrm{~m}^{3} \text { day }^{-1} \\
& \sum Q_{i}^{10}=Q_{W 1}^{10}+Q_{W 2}^{10}+\ldots \ldots \ldots . .+Q_{W 18}^{10}=-22464 m^{3} \text { day }^{-1} \\
& \sum Q_{i}^{11}=Q_{W 1}^{11}+Q_{W 2}^{11}+\ldots \ldots \ldots .+Q_{W 18}^{11}=-23464 m^{3} \text { day }^{-1} \\
& \sum Q_{i}^{12}=Q_{W 1}^{12}+Q_{W 2}^{12}+\ldots \ldots \ldots . .+Q_{W 18}^{12}=-20464 m^{3} \text { day }^{-1}
\end{aligned}
$$

\section{CONCLUSIONS}

In the present paper the optimization of the total flow and heads, subject to a given set of constraints, must be accomplished. For this purpose a model is developed by combining the well-known groundwater model MODFLOW with the management models MODMAN and LINDO.

The model chosen provides flexible tools for analyzing water-system behavior under varying conditions and operating policies. Although Linear Programming approach is applicable only to models whose objective function and constraints are linear functions of the decision variables, however, can produce high quality solutions in terms of both accuracy and computer time required. The optimization technique enables a large number of scenarios, regarding operational criteria for the existing wells.

- The optimum values of piezometric heads and flow rates are shown in table 1 and 2 , respectively.

- The piezometric level in well $W_{11}$ is too high in modopt file. Therefore, located in the same cell as spring 2 , well $W_{11}$ is considered by the program as a spring.

- The mean annual pumping cost, determined by the optimization procedure, taking into consideration the cost of wells function, as well as the workers salary, is $19635,73 €$.

- As it can be seen from figure 2, wells named $W_{14}, W_{15}, W_{16}, W_{17}, W_{18}$ are located close to each other, having as a result the low piezometric head of the aquifer in that region. In order to avoid high drawdowns in a specific area of the aquifer, the optimum solution will have to recommend the most effective way for pumping, bearing in mind the capacity of the system and the demand for water.

- Optimum values on table 2 indicate that wells named $W_{5}$ and $W_{7}$ reach the $90 \%$ of the total pumping rate in January, while in September this percentage changes to a $45 \%$. This seems to be quite logical, taking into account that, initial rates of the above wells cover a $65 \%$ of total in January and $33 \%$ in September, respectively. On the other hand, this can be easily explained, because both wells $W_{5}$ and $W_{7}$ are situated in a discharging area, dominated mostly by $P_{1}$ and $P_{2}$ springs. 
Table 1. Optimum piezometric levels in control points $(\mathrm{m})$

\section{9th MONTH \\ (END OF PUPMING \\ PERIOD)}

\begin{tabular}{|c|c|c|c|c|c|c|}
\hline $\mathbf{a} / \mathbf{a}$ & Wells & $\begin{array}{c}\text { Initial } \\
\text { piezometric } \\
\text { head }\end{array}$ & $\begin{array}{c}\text { Minimum } \\
\text { value }\end{array}$ & $\begin{array}{c}\text { Optimum } \\
\text { solution }\end{array}$ & $\begin{array}{c}\text { Minimum } \\
\text { value }\end{array}$ & $\begin{array}{c}\text { Optimum } \\
\text { solution }\end{array}$ \\
\hline 1 & $\mathbf{W}_{\mathbf{1}}$ & 99,45 & 32,00 & 94,98 & 42,00 & 64,79 \\
\hline 2 & $\mathbf{W}_{\mathbf{2}}$ & 77,74 & 32,00 & 46,75 & 41,00 & 41,00 \\
\hline 3 & $\mathbf{W}_{\mathbf{4}}$ & 96,40 & 27,00 & 27,00 & 45,00 & 53,38 \\
\hline 4 & $\mathbf{W}_{\mathbf{5}}$ & 94,20 & 27,00 & 27,00 & 37,00 & 55,47 \\
\hline 5 & $\mathbf{W}_{\mathbf{6}}$ & 94,73 & 25,00 & 28,10 & 38,00 & 58,56 \\
\hline 6 & $\mathbf{W}_{\mathbf{7}}$ & 107,59 & 25,00 & 27,70 & 35,00 & 57,98 \\
\hline 7 & $\mathbf{W}_{\mathbf{8}}$ & 263,12 & 26,00 & 29,73 & 35,00 & 59,50 \\
\hline 8 & $\mathbf{W}_{\mathbf{1 1}}$ & 97,99 & 35,00 & - & 47,00 & - \\
\hline 9 & $\mathbf{W}_{\mathbf{1 4}}$ & 95,42 & 25,00 & 25,00 & 34,00 & 69,05 \\
\hline 10 & $\mathbf{W}_{\mathbf{1 5}}$ & 147,53 & 27,00 & 42,04 & 34,00 & 70,28 \\
\hline 11 & $\mathbf{W}_{\mathbf{1 6}}$ & 103,60 & 26,00 & 36,91 & 35,00 & 70,62 \\
\hline 12 & $\mathbf{W}_{\mathbf{1 7}}$ & 167,87 & 25,00 & 122,40 & 34,00 & 90,42 \\
\hline 13 & $\mathbf{W}_{\mathbf{1 8}}$ & 89,86 & 36,00 & 36,00 & 34,00 & 69,61 \\
\hline
\end{tabular}

Table 2. Optimum flow rates for all time periods $\left(\mathrm{m}^{3}\right.$ day $\left.^{-1}\right)$

\begin{tabular}{|c|c|c|c|c|c|c|c|c|c|c|c|c|c|}
\hline $\mathbf{a} / \mathbf{a}$ & $\mathbf{W e l l s}$ & $\mathbf{J}$ & $\mathbf{F}$ & $\mathbf{M}$ & $\mathbf{A}$ & $\mathbf{M}$ & $\mathbf{J}$ & $\mathbf{J}$ & $\mathbf{A}$ & $\mathbf{S}$ & $\mathbf{O}$ & $\mathbf{N}$ & $\mathbf{D}$ \\
\hline 1 & $\mathbf{W}_{\mathbf{1}}$ & 739 & 739 & 739 & 739 & 739 & 739 & 739 & 739 & 739 & 739 & 739 & 739 \\
\hline 2 & $\mathbf{W}_{\mathbf{2}}$ & 0 & 0 & 4200 & 4200 & 6000 & 6000 & 6000 & 6000 & 6000 & 4200 & 4200 & 4200 \\
\hline 3 & $\mathbf{W}_{\mathbf{4}}$ & 1000 & 1000 & 1000 & 1000 & 1000 & 1000 & 1000 & 1000 & 3251 & 1000 & 1000 & 1000 \\
\hline 4 & $\mathbf{W}_{\mathbf{5}}$ & 11765 & 9182 & 13565 & 12565 & 16370 & 16370 & 16370 & 16370 & 9825 & 8565 & 9565 & 6401 \\
\hline 5 & $\mathbf{W}_{\mathbf{6}}$ & 100 & 1715 & 100 & 100 & 1715 & 1715 & 1715 & 1715 & 1715 & 100 & 100 & 100 \\
\hline 6 & $\mathbf{W}_{\mathbf{7}}$ & 7560 & 7560 & 7560 & 7560 & 10800 & 10800 & 10800 & 10800 & 10800 & 7560 & 7560 & 7560 \\
\hline 7 & $\mathbf{W}_{\mathbf{8}}$ & 100 & 100 & 100 & 100 & 2905 & 2905 & 2905 & 2905 & 2905 & 100 & 100 & 99 \\
\hline 8 & $\mathbf{W}_{11}$ & 100 & 168 & 100 & 100 & 100 & 100 & 100 & 100 & 100 & 100 & 100 & 264 \\
\hline 9 & $\mathbf{W}_{\mathbf{1 2}}$ & 0 & 0 & 0 & 0 & 238 & 238 & 238 & 238 & 238 & 0 & 0 & 0 \\
\hline 10 & $\mathbf{W}_{\mathbf{1 4}}$ & 100 & 0 & 100 & 100 & 7868 & 7868 & 6868 & 7868 & 168 & 100 & 100 & 100 \\
\hline 11 & $\mathbf{W}_{\mathbf{1 5}}$ & 0 & 0 & 0 & 0 & 100 & 100 & 100 & 100 & 3432 & 0 & 0 & 0 \\
\hline 12 & $\mathbf{W}_{\mathbf{1 6}}$ & 0 & 0 & 0 & 0 & 100 & 100 & 100 & 100 & 100 & 0 & 0 & 0 \\
\hline 13 & $\mathbf{W}_{\mathbf{1 7}}$ & 0 & 0 & 0 & 0 & 100 & 100 & 100 & 100 & 4224 & 0 & 0 & 0 \\
\hline 14 & $\mathbf{W}_{\mathbf{1 8}}$ & 0 & 0 & 0 & 0 & 100 & 100 & 100 & 100 & 2640 & 0 & 0 & 0 \\
\hline
\end{tabular}

*all flow rates are pumping rates

\section{REFERENCES}

Arnold H. Lobbrecht (1994) Operations modeling for control of rural water management systems, Advances in Water Resources Technology and Management, Tsakiris \& Santos (eds), Balkema, Rotterdam.

Reeve A.S. et al. (1999) Simulating vertical flow in large petlands, Journal of Hydrology, 227: 207217.

Bear, J. (1979) Hydraulics of Groundwater, McGraw Hill Book Company, London.

Colarullo et al. (1984). Identification of an optimal groundwater management strategy in a contaminated aquifer, Water Recourses Bulletin, 20 (5), 747-760. 
Ginidi P. (2002). Management of Aghia Varvara's aquifer of Drama by applying Linear Programming, MSc Thesis, AUTH, Thessaloniki, Greece.

Greenwald, R.M. (1994). MODflow MANagement: An Optimization Module for MODFLOW, IGWMC, version 3.02.

Mc Donald M.G., and Harbaugh A.W. (1988). A modular three - dimensional finite - difference groundwater flow model, U.S. Geological Survey, Techniques of Water Resources Investigations, Book 6, Chapter A1.

Garg N.K., Abbas Ali (1998). Two-level optimization model for Lower Indus Basin, Agricultural Water Management, 36: 1-27.

Psilovikos A. (1998). Optimization Models in Groundwater Management, Based on Linear and Mixed Integer Programming. An application to a Greek Hydrogeological Basin, Phys. Chem. Earth (B), 24 (1-2), 139-144.

Psilovikos A. and Tzimopoulos C., (1998). Pumping cost analysis in groundwater management, using the MODMAN (MODflow MANagement) model. Proc. $12^{\text {th }}$ International Conf. On Computational Methods In Water Resources, Crete, Greece.

Psilovikos A. (1999). Optimization Models in Groundwater Management, Based on Linear and Mixed Integer Programming. An application to a Greek Hydrological Basin, Phys. Chem. Earth (B), 24 (1-2), 139-144.

Research program "Water resources in Aghia Varvara of Drama», AUTH 1997, Thessaloniki, Greece.

Schrage, L., (1991), LINDO the user's manual, Release 5.0, The scientific Press, San Francisco, $132 \mathrm{pp}$.

Schwarz J., (1971). Linear Models for Groundwater management. Water planning for Israel. Ltd. Israel, P.N. ET/71/062. 